\title{
Preliminary design setup and experimental results of laser sintering for use in aerosol jet printing
}

\author{
Michael D. McMurtrey \\ Stephen J. Reese
}

April 2018

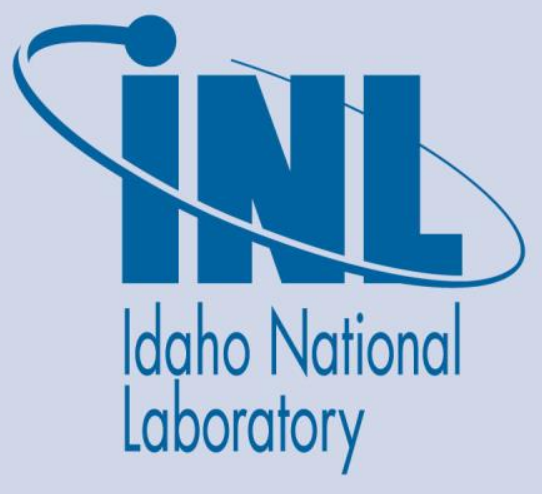

The INL is a U.S. Department of Energy National Laboratory operated by Battelle Energy Alliance 


\section{DISCLAIMER}

This information was prepared as an account of work sponsored by an agency of the U.S. Government. Neither the U.S. Government nor any agency thereof, nor any of their employees, makes any warranty, expressed or implied, or assumes any legal liability or responsibility for the accuracy, completeness, or usefulness, of any information, apparatus, product, or process disclosed, or represents that its use would not infringe privately owned rights. References herein to any specific commercial product, process, or service by trade name, trade mark, manufacturer, or otherwise, does not necessarily constitute or imply its endorsement, recommendation, or favoring by the U.S. Government or any agency thereof. The views and opinions of authors expressed herein do not necessarily state or reflect those of the U.S. Government or any agency thereof. 
INL/EXT-18-45196

Revision 0

\section{Preliminary design setup and experimental results of laser sintering for use in aerosol jet printing}

Michael D. McMurtrey

Stephen J. Reese

April 2018

Idaho National Laboratory Idaho Falls, Idaho 83415

http://www.inl.gov

Prepared for the

U.S. Department of Energy

Office of Nuclear Energy

Under DOE Idaho Operations Office

Contract DE-AC07-05ID14517 



\title{
Preliminary design setup and experimental results of laser sintering for use in aerosol jet printing
}

\author{
INL/EXT-18-45196 \\ Revision 0
}

April 2018

Approved by:

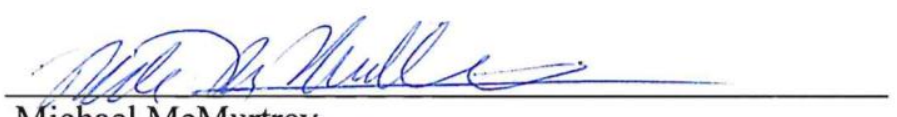

Michael McMurtrey

I3 Work Package Manager, Advanced manufacturing

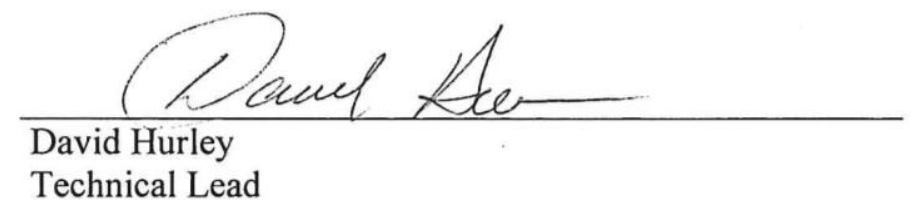

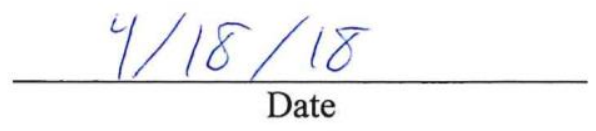

$\frac{4-18-18}{\text { Date }}$ 


\section{SUMMARY}

It is imperative to understand the application of emerging advanced manufacturing techniques to nuclear related capabilities. The Advanced Manufacturing thrust of the In-Pile Instrumentation Initiative seeks to apply techniques such as aerosol jet printing to allow for manufacturing of novel sensor designs. As part of this thrust, a laser sintering system is being developed. The preliminary design allows for benchtop experiments that are controlled with a manual stage. The preliminary results did not appear to achieve sufficient temperatures to sinter the specimen, and temperatures were not accurately measured by the IR camera. A calibration to link silver emissivity with temperature must be performed in order to quantitatively measure temperatures with the IR camera. This calibration will be performed, and a second sintering experiment performed in detail to determine required laser exposure times and temperatures to achieve sintering with the system. Future updates for the system include a higher resolution lens for the IR camera to allow for higher magnification temperature observations, as well as a motorized stage and control framework to link the stage movements to the specimen geometry and desired exposure time during the sintering process. 


\section{CONTENTS}

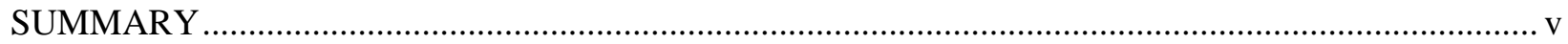

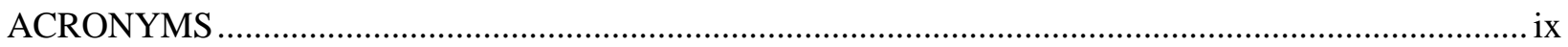

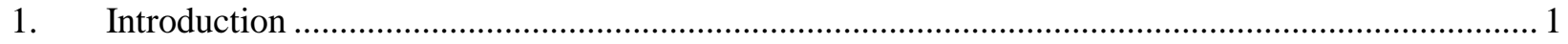

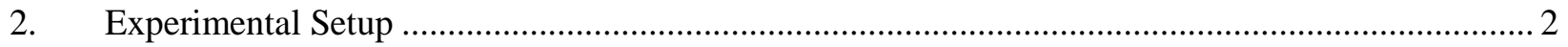

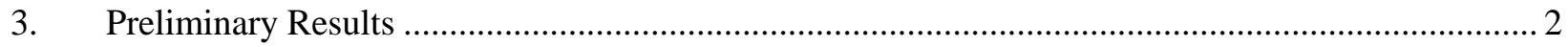

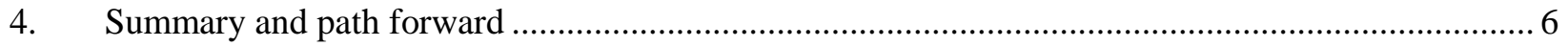

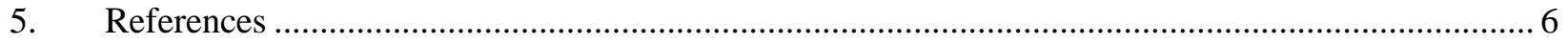

\section{FIGURES}

Figure 1. Schematic (left) and image (right) of the preliminary design of the INL Laser Sintering System. The image shows the lens, as well as the stage and specimen..................................... 2

Figure 2. Laser induced burn marks on photographic paper used to estimate the laser spot size................ 3

Figure 3. $(a, b, c)$ Optical images of the unsintered AJP printed silver specimen received at INL, as well as (d,e) optical images of a specimen sintered at BSU inside an argon atmosphere furnace at $300^{\circ} \mathrm{C}$ for 30 minutes

Figure 4. $(a, b, c)$ SEM images of the unsintered AJP printed silver specimen received at INL, as well as (d,e) SEM images of a specimen sintered at BSU inside an argon atmosphere furnace at $300^{\circ} \mathrm{C}$ for 30 minutes.

Figure 5. IR camera images during preliminary experiments showing hot spot created during laser exposure. Qualitatively, the red/orange areas represent areas of elevated temperature, whereas the green/blue areas are cooler temperatures. Additional work is needed to calibrate the signal to determine quantitative temperatures. 


\section{ACRONYMS}

AJP - Aerosol Jet Printing

BSU - Boise State University

INL - Idaho National Laboratory

IR - Infrared

SEM - Scanning Electron Microscope 


\section{Preliminary design setup and experimental results of laser sintering for use in aerosol jet printing}

\section{Introduction}

Despite significant research effort on additive manufacturing methods for sensors in aerospace and other industries, printed sensors have remained underexplored in the nuclear industry. The In-Pile Instrumentation Initiative is conducting research needed to develop and deploy novel instruments to monitor and characterize the behavior of fuels and materials during in-pile irradiations within test reactors. Real time data is key to running safe and efficient reactors, however, the harsh environment within a reactor core makes this a challenging problem. To address these challenges, novel sensor designs are being developed to allow for use within the reactor core, as well as to reduce the size (and footprint on the nuclear fuel/cladding). The final goal of the program is to provide accurate, spatially resolved information regarding the performance of fuels and materials during irradiation in-pile, rather than the current method of relying on post irradiation ex-situ examination.

The advanced manufacturing thrust of this program is developing advanced manufacturing techniques and capabilities necessary to enable transformative sensor technology for in-pile monitoring and in-situ analysis. Advanced manufacturing refers to a number of different techniques that use innovative technology to improve the manufacturing processes over traditional methods (traditional methods include methods such as casting, forging, welding and machining). These improvements include the ability to form complex geometries without welds or solder joints, to form graded materials with seamless composition gradients or changes, and to form components directly on the desired substrates. Advanced manufacturing techniques will significantly accelerate the feedback loop of designing, modeling, fabricating and testing novel sensor designs. Additionally, advanced manufacturing techniques will provide a diverse set of tools to develop and deploy an array of sensors that will enable significant improvements in spatial resolution, data quality, and measurement accuracy.

Aerosol jet printing (AJP) has been identified as the most versatile manufacturing technique for fabricating sensors with micron and sub-micron dimensional geometries, which covers many of the novel sensor designs. AJP refers to the process of laying down droplets of inks, which are suspensions of a carrier liquid and nanoparticles of the material of interest, and subsequently drying and sintering to additively manufacture the component of interest. It has been used already to create components for the cellular telephone and aerospace industries. [1,2] Additional work is needed to develop the inks necessary to print all of the sensor materials, as well as optimize the method for printing and sintering the materials to consistently create reliable sensors.

As part of the printing process, the Idaho National Laboratory (INL) is working to develop a laser sintering system that will allow for in-situ material sintering as the printer is laying down the ink. This will allow for increased flexibility in designs and material choice, especially in terms of changing materials in the same build area (e.g. alloying elements or creating melt wires of different compositions in close proximity). It will also allow for a higher degree of control and optimization than is allowed for by typical ex-situ (post print completion) sintering within a furnace, resulting in more reliable sensor fabrication. 


\section{Experimental Setup}

The sintering systems will be composed of five parts: A laser source, the necessary optics (lenses) for focusing and directing the laser, motorized stages, an IR camera for temperature monitoring, and a control framework (control software). The layout of the hardware is shown in Figure 1. Also shown in Figure 1 is the setup used for preliminary testing of the system. The preliminary test included everything except the control framework and motorized stages (manual stages, controlled with micrometers allowed for movement along the two in-plane axes). Unsintered AJP printed silver specimens were provided by Boise State University (BSU).
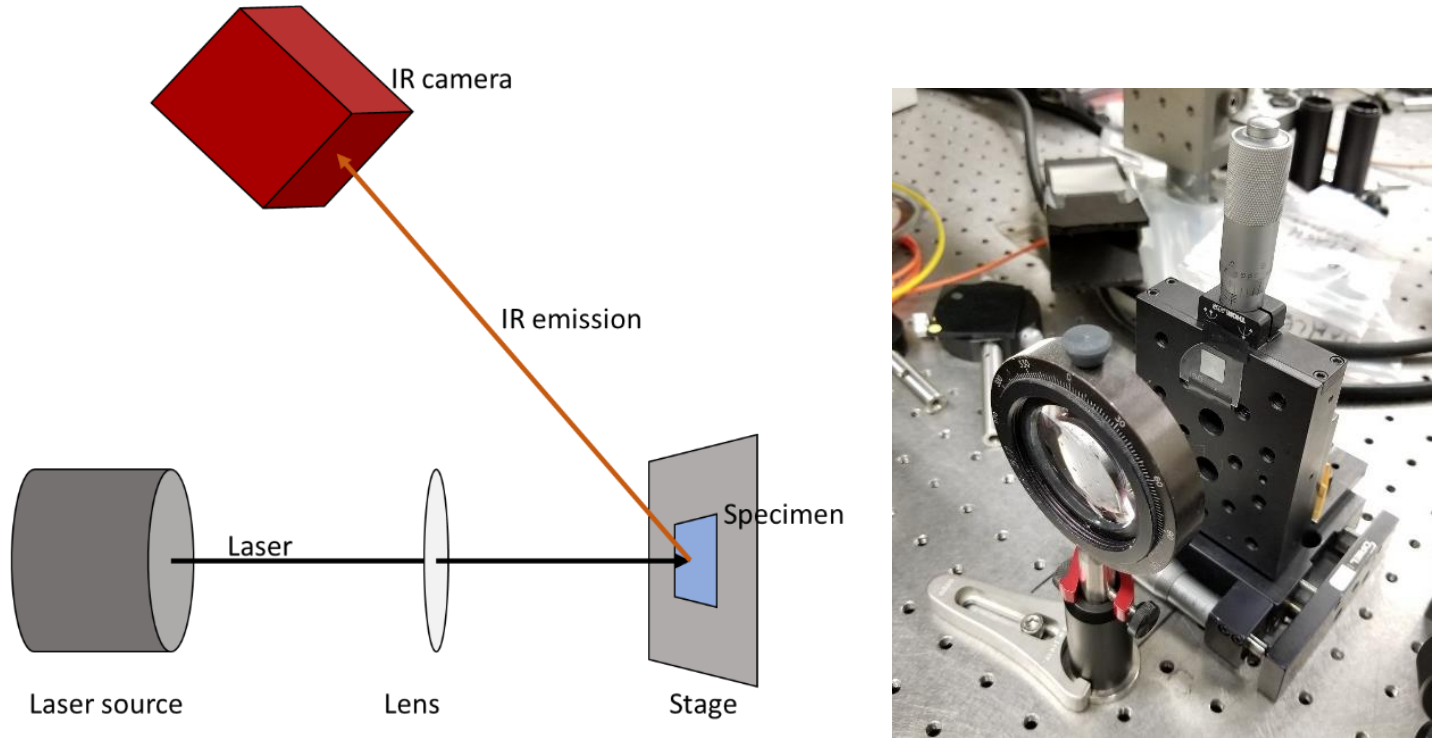

Figure 1. Schematic (left) and image (right) of the preliminary design of the INL Laser Sintering System. The image shows the lens, as well as the stage and specimen.

The first experiment performed on this system was an examination of several "spot" sinterings performed for varying lengths of time. The laser was directed towards the unsintered silver specimens while the IR camera measured temperature. Following the sintering at a single spot, the location of the laser relative to the specimen was changed by manually adjusting the stage that held the specimen to create new spot where the laser was directed for an increased amount of time. These "spot" sintering experiments allow for examination into necessary sintering times for a given laser power.

\section{Preliminary Results}

Prior to performing the spot sintering experiments, an estimation of the laser spot size was determined by exposing photographic paper to the laser and measuring the burned area. The results are shown in Figure 2, and the laser spot size was determined to be approximately $275 \mu \mathrm{m}$. 


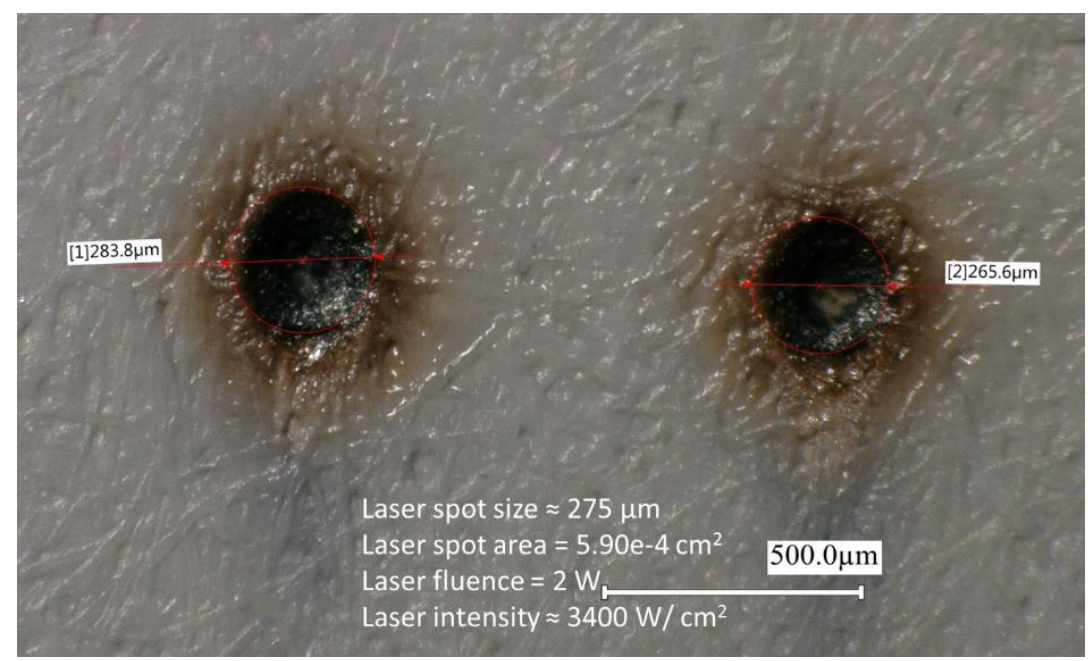

Figure 2. Laser induced burn marks on photographic paper used to estimate the laser spot size.

Images were taken of the unsintered specimens received by INL from BSU to determine the original state of the material and provide a comparison for sintered areas. These are shown in Figures $3 \mathrm{a}, 3 \mathrm{~b}, 3 \mathrm{c}$, $4 \mathrm{a}, 4 \mathrm{~b}$, and $4 \mathrm{c}$. Images taken of a similar specimen sintered at BSU in an argon atmosphere furnace at $300^{\circ} \mathrm{C}$ for 30 minutes are shown in Figures $3 \mathrm{~d}, 3 \mathrm{e}, 4 \mathrm{~d}$, and $4 \mathrm{e}$. Images taken by an optical microscope are shown in Figure 3, whereas Figure 4 shows images taken from within a scanning electron microscope (SEM). Smaller, discrete particles are visible in the unsintered images, whereas the material is more continuous post sintering (though a significant presence of voids is noted). 


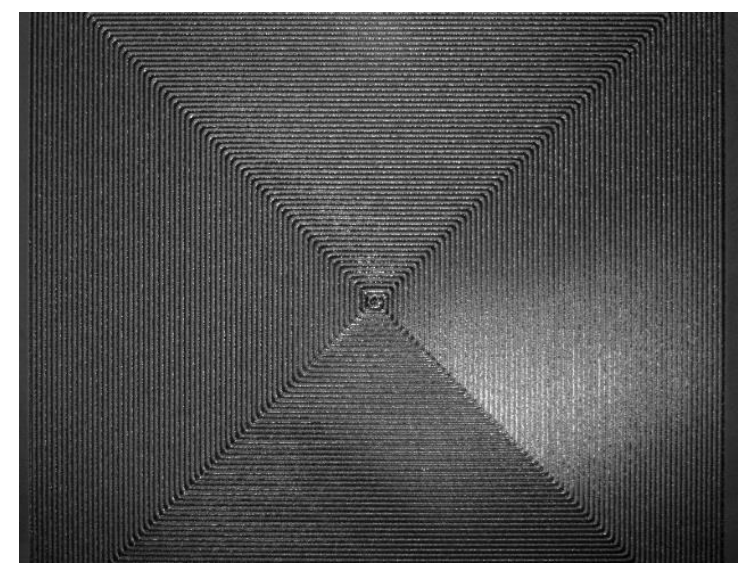

(a)

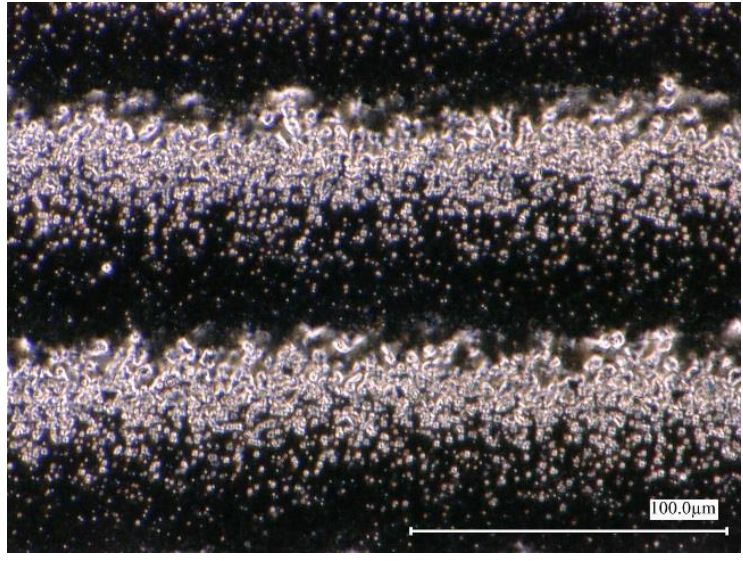

(c)

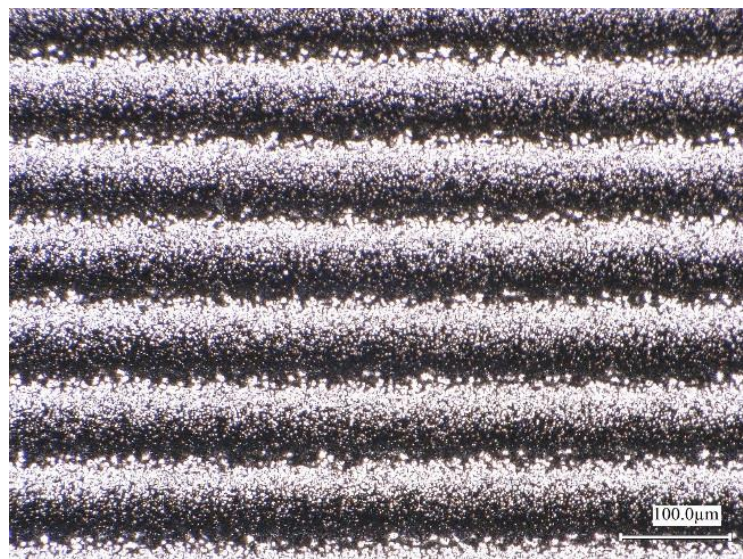

(b)

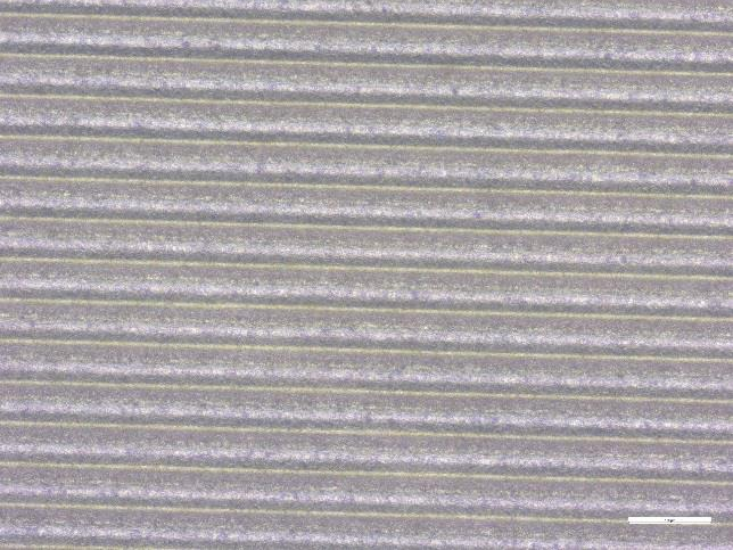

(d)

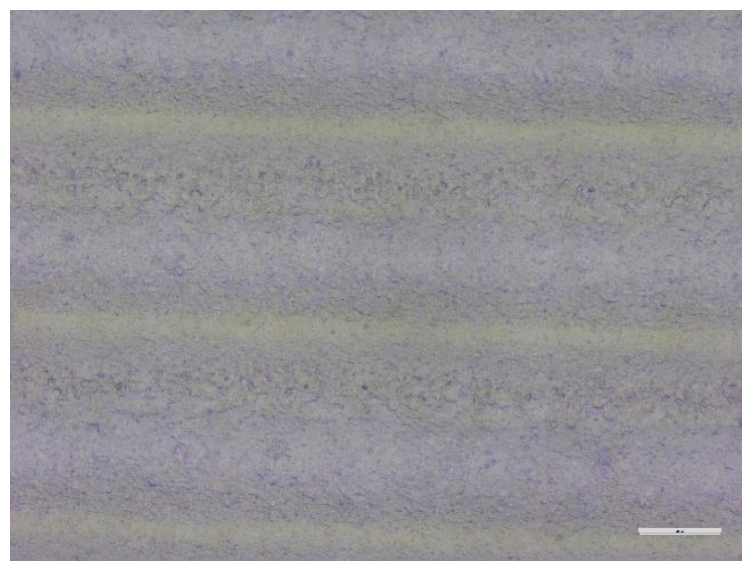

(e)

Figure 3. (a,b,c) Optical images of the unsintered AJP printed silver specimen received at INL, as well as $(\mathrm{d}, \mathrm{e})$ optical images of a specimen sintered at BSU inside an argon atmosphere furnace at $300^{\circ} \mathrm{C}$ for 30 minutes. 

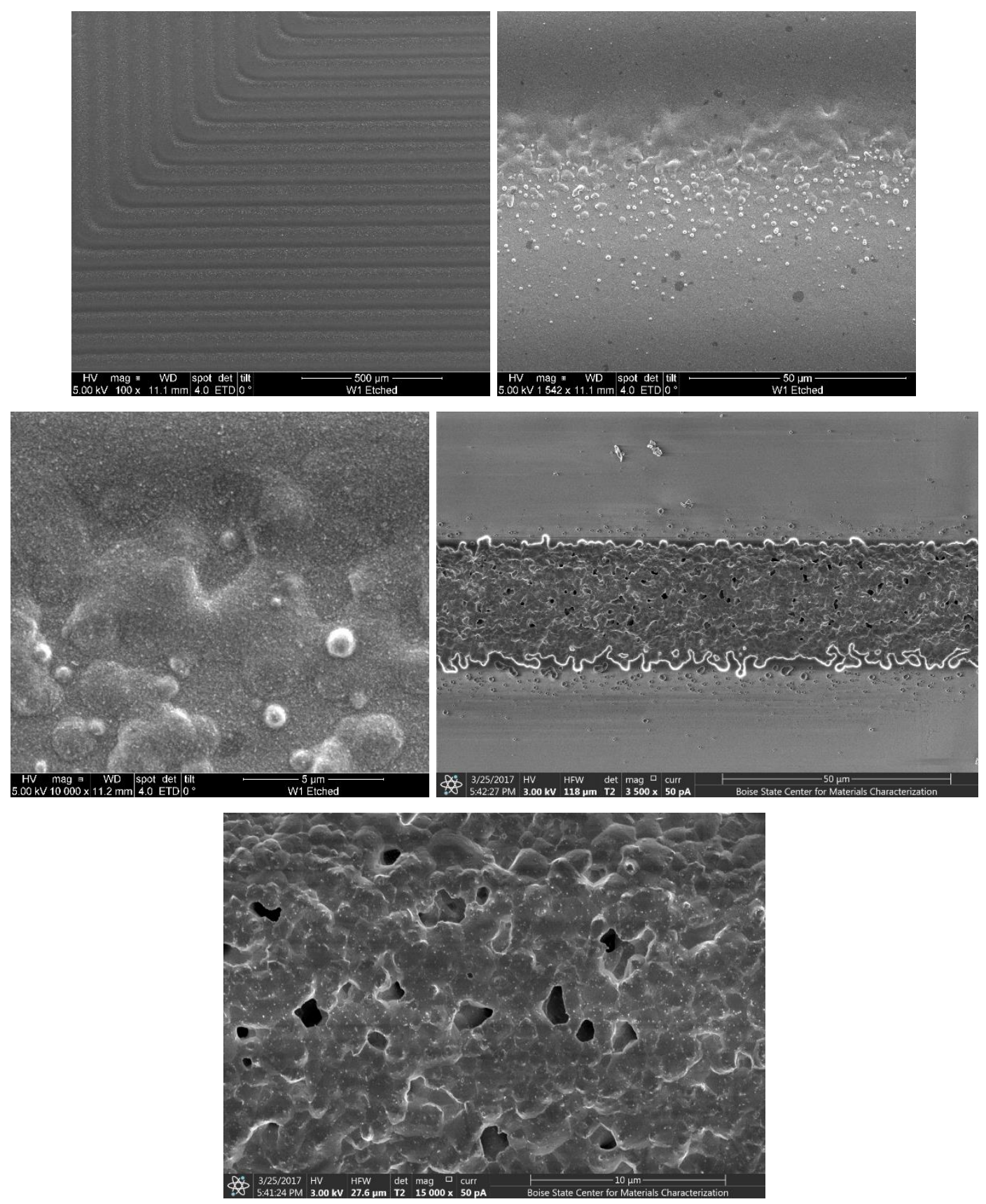

Figure 4. $(a, b, c)$ SEM images of the unsintered AJP printed silver specimen received at INL, as well as $(\mathrm{d}, \mathrm{e}) \mathrm{SEM}$ images of a specimen sintered at BSU inside an argon atmosphere furnace at $300^{\circ} \mathrm{C}$ for 30 minutes.

During the spot sintering experiments, it was noted that, while the IR camera showed elevated temperatures where the laser interacted with the silver specimen (as seen in Figure 5), actual temperature measurements were not possible, due to the need to calibrate emissivity of silver with temperature. In addition to the calibration, to acquire accurate maximum temperature readings, a higher resolution lens (macro lens or microscope objective) will be required. At the current resolution the laser spot size is less than one pixel in diameter. Following the attempts to perform the spot sintering without accurate temperature monitoring, no difference was observed in the specimens with optical microscopy. A second 
round of experiments will be performed with more accurate temperature monitoring, which will allow for determining needed temperatures and times required to sinter with the laser sintering system.
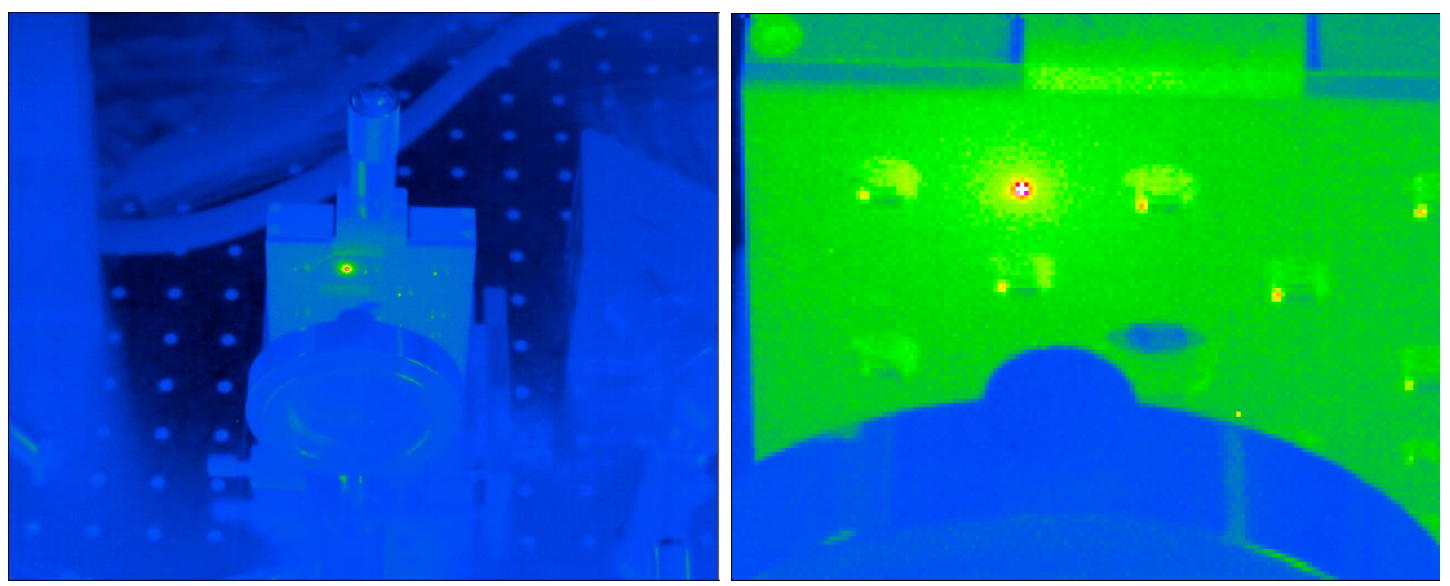

Figure 5. IR camera images during preliminary experiments showing hot spot created during laser exposure. Qualitatively, the red/orange areas represent areas of elevated temperature, whereas the green/blue areas are cooler temperatures. Additional work is needed to calibrate the signal to determine quantitative temperatures.

\section{Summary and path forward}

It is imperative to understand the application of emerging advanced manufacturing techniques to nuclear related capabilities. The Advanced Manufacturing thrust of the In-Pile Instrumentation Initiative seeks to apply techniques such as AJP to allow for manufacturing of novel sensor designs. As part of this thrust, a laser sintering system is being developed. The preliminary design allows for benchtop experiments that are controlled with a manual stage. The preliminary results did not appear to achieve sufficient temperatures to sinter the specimen, and temperatures were not accurately measured by the IR camera. A calibration to link silver emissivity with temperature will need to be performed to obtain quantitative temperature measurements with the IR camera. This calibration will be performed, and a second sintering experiment performed in detail to determine required laser exposure times and temperatures to achieve sintering with the system. Future updates for the system include a higher resolution lens for the IR camera to allow for higher magnification temperature observations, as well as a motorized stage and control framework to link the stage movements to the specimen geometry and desired exposure time during the sintering process.

\section{References}

[1] M. Austin, "Systems Health Monitoring - From Ground to Air - The Aerospace Challenges," AIP Conf. Proc., vol. 894, no. 1, pp. 1477-1484, 2007.

[2] J. A. Paulsen, M. Renn, K. Christenson, and R. Plourde, "Printing conformal electronics on 3D structures with Aerosol Jet technology," in 2012 Future of Instrumentation International Workshop (FIIW) Proceedings, 2012, pp. 1-4. 